\title{
CAFEICULTURA TRATAMENTO QUÍMICO, TÉRMICO E BIOLÓGICO DE SOLO PARA CONTROLE DE Meloidogyne exigua NA FORMAÇÃO DE MUDAS DE Coffea arabica
}

\author{
COFFEE CULTURE CHEMICAL, THERMAL AND BIOLOGICAL \\ TREATMENT OF SOIL FOR CONTROL OF Meloidogyne exigua IN THE \\ FORMATION OF Coffea arabica SEEDLINGS
}

\author{
${ }^{1}$ José Carlos Lambert \\ ${ }^{2}$ Jadier de Oliveira Cunha Junior \\ $3^{3 *}$ Antonio Fernando de Souza \\ ${ }^{4}$ Fábio Ramos Alves
}

\begin{abstract}
${ }^{1}$ Instituto Federal do Espírito Santo, Campus Santa Teresa. E-mail: jose.lambert@ifes.edu.br
${ }^{2}$ Instituto Federal do Espírito Santo, Campus Itapina. E-mail: jadier.cunha@ifes.edu.br. ${ }^{3}$ Instituto Federal do Espírito Santo, Campus Santa Teresa. E-mail: antonio.fernando@ifes.edu.br ${ }^{4}$ Universidade Federal do Espírito Santo, Campus Alegre. E-mail: fabioramosalves@yahoo.com.br *Autor de correspondência.
\end{abstract}

Artigo submetido em 30/09/2020, aceito em 04/10/2020 e publicado em 23/12/2020.

\begin{abstract}
Resumo: A cafeicultura é a principal atividade agrícola no Espírito Santo (ES). Os nematoides são causadores de considerável perda na produção, cujos cuidados, devem iniciar-se com a formação das mudas. A maioria dos viveiristas de café do ES utilizam basicamente solo como substrato, o qual pode estar infestado por nematoides. Com o intuito de potencializar o controle de Meloidogyne exigua no substrato, avaliou-se a associação dos tratamentos biológico, químico e térmico em solo naturalmente infestado, usado para produção de mudas de Coffea arabica. O experimento foi conduzido no viveiro do Instituto Federal do Espírito Santo, campus Santa Teresa. O delineamento experimental foi em blocos ao acaso, em esquema fatorial $4 \times 2$, em três repetições, totalizando 24 unidades experimentais. Cada unidade foi composta por oito sacolas contendo, individualmente, o respectivo substrato tratado e uma muda de café arábica. No fator um os tratamentos foram: 1 - Solo infestado não tratado; 2 - Solo infestado tratado com metam-sódico; 3 - Solo infestado tratado com dazomete; 4 - Solo infestado tratado com energia solar. No fator dois foram: 1 - não incorporação de Pochonia chlamydosporia e 2 - incorporação do P. chlamydosporia aos respectivos substratos. Avaliou-se a população final de nematoides e a eficiência de controle aos 180 dias após tratamentos. Os tratamentos térmico e químico do substrato, associados ou não a $P$. chlamydosporia, reduziram significativamente o número de galhas, a população de nematoides (ovos $+\mathrm{J} 2$ ) nas raízes e melhoraram a eficiência do controle de $M$. exigua em relação ao substrato não tratado.
\end{abstract}

Palavras-chave: nematoide das galhas; fumigantes de solo; coletor solar; Pochonia chlamydosporia.

Abstract: Coffee growing is the main agricultural activity in Espírito Santo (ES). Nematodes cause considerable loss in production, special care, must start with the formation of seedlings. Most coffee nurseries in ES basically use soil as a substrate, which may be infested by nematodes. In order to potentialize the control of Meloidogyne exigua in the substrate used, the association of biological 
treatment, chemical and thermal in naturally infested soil, used for the production of Coffea arabica seedlings, was evaluated. The experiment was carried out at Federal Institute of Espírito Santo, Santa Teresa campus. The experimental design was in randomized blocks, in a $4 \times 2$ factorial scheme, in three replications, totaling 24 experimental units. Each unit was composed of eight bags individually, the respective substrate and an arabica coffee seedling. In factor one, the treatments were: 1 - Untreated infested soil; 2 - Infested soil treated with metam-sodium; 3 - Infested soil treated with dazomet; 4 - Infested soil treated with solar energy. In factor two were: 1 - non-incorporation of Pochonia chlamydosporia and 2 - incorporation of P. chlamydosporia to the respective substrates. The final nematode population and control efficiency were evaluated 180 days after treatments. The thermal and chemical treatments of the substrate, associated or not with P. chlamydosporia, reduced the number of galls, the nematode population (eggs $+\mathrm{J} 2$ ) in the roots and improved the efficiency of the M. exigua control in relation to the untreated substrate.

Keywords: root-knot nematode; soil fumigants; solar collector; Pochonia chlamydosporia.

\section{INTRODUÇÃO}

O café chegou ao norte do Brasil em 1727 trazido da Guiana Francesa por Francisco de Melo Palheta e seguiu para o Rio de Janeiro por volta de 1760 . Do Rio de Janeiro para São Paulo e em seguida para Bahia e Minas Gerais. A partir do início da década de 1880 o Brasil se tornou o maior produtor mundial de café e passa a representar novas oportunidades de desenvolvimento e grande movimentação de capital, processo pelo qual se tornou conhecido como o "ciclo do café" (BELTRÃO, 2018).

O Brasil segue como maior produtor e exportador mundial de café. A Companhia Nacional de Abastecimento em seu terceiro levantamento de acompanhamento da safra brasileira de café 2020, indicou uma produção de 61,6 milhões de sacas de $60 \mathrm{~kg}$, com crescimento de $25 \%$ em relação a safra 2019. A produção estimada para o café arábica é de 47,4 milhões de sacas e para o conilon é de 14,3 milhões. O estado de Minas Gerais (MG), maior produtor nacional, deverá responder por 54,4\% da safra e o Espírito Santo (ES), segundo maior produtor, por 22\% (CONAB, 2020). Em 2019 o país exportou 40,6 milhões de sacas para 128 países, batendo novo recorde e somando US\$ 5,1 bilhões para a balança comercial brasileira (CECAFE, 2019).
Apesar do destaque brasileiro na produção e exportação de café, os cafeicultores têm enfrentado diversos obstáculos à sua produtividade, dentre eles o nematoide das galhas (Meloidogyne spp.), causadores de consideráveis perdas e com ampla disseminação e distribuição nas plantações de café no Brasil. A espécie $M$. exigua ocorre em praticamente todas as regiões de cultivo de café arábica (CAMPOS \& VILLAIN, 2005).

Em estudo para estabelecer a distribuição geográfica de espécies de Meloidogyne em 18 municípios produtores de café da região Norte, Sul e Serrana do ES, Barros (2010) detectou M. incognita em lavouras de $C$. canephora, em $18 \%$ das propriedades amostradas e $M$. exigua em lavouras de C. arabica, em $43 \%$ das propriedades. A disseminação desses fitonematoides a longas distâncias ocorre por meio de mudas infestadas (FERRAZ \& BROWN, 2016).

A cafeicultura é a principal atividade agrícola do ES, presente em quase todos os municípios e em dois terços das propriedades rurais capixaba (SEAG, 2019). A atividade se inicia com a produção das mudas, que no período $2016 \backslash 2017$ foi de 84,5 milhões de unidades, produzidas em 41 municípios capixabas, conforme inscrição no Ministério da Agricultura, Pecuária e Abastecimento (MAPA, 2017). A maioria dos produtores de mudas de café do ES, 
principalmente de arábica, utiliza solo como substrato, o qual, sem controle pode estar infestado por nematoides e chegar ao viveiro trazendo ovos e juvenis de Meloidogyne spp. e consequentemente, provendo a formação de mudas infestadas pelo patógeno.

Até a década de 1980, o solo utilizado como substrato para produção de mudas de café no Brasil, passava por desinfecção química, através de brometo de metila - produto de maior eficiência no tratamento de substratos. Posteriormente teve seu uso suspenso por representar riscos à saúde humana. Atualmente existem três moléculas registradas para manejo de nematoides em cafeeiro. No entanto, Lima et al. (2019) ressaltaram que o controle químico reduz a população de nematoides por 60 a 70 dias após aplicação, permitindo aumentar novamente com o fim do efeito residual dos produtos.

Outros métodos são estudados na busca de alternativas mais sustentáveis ao convencional método químico de controle fitossanitário. O tratamento térmico do solo através da energia solar é um processo não-químico que tem provado eficácia no controle de patógenos de solo, de plantas daninhas e ao mesmo tempo favorece os microrganismos benéficos do solo (ROCHA \& CARNEIRO, 2016). Esse processo consiste no tratamento do solo, dentro do coletor solar, o qual converte a energia solar em energia calorífica, que alcançam valores de temperatura superiores a $50^{\circ} \mathrm{C}$. Esta temperatura é suficiente para eliminar os principais microrganismos do solo como fungos, bactéria, vírus e nematoides (VIEIRA JÚNIOR et al., 2016).

No entanto, estudos têm revelado que tanto o método químico, quanto o térmico por energia solar, não eliminam completamente o inóculo de Meloidogyne spp. no solo infestado para produção de mudas de café (RODRIGUES, 2015; BRUMAT, 2015).
O controle biológico dentro do manejo integrado tem ganhado destaque por ser um método sustentável, de acesso a organismos de fácil produção in vitro e pela possibilidade de algumas espécies colonizarem a rizosfera das plantas (SILVA, 2015). Dentre os agentes de controle biológico de fitonematoides, destaca-se o fungo Pochonia chlamydosporia (BARBOSA et al., 2019). Esse fungo coloniza a superfície das raízes das plantas e parasita ovos e fêmeas produzidos por Meloidogyne spp. reduzindo o inóculo inicial do patógeno no solo (WARD et al., 2012), tanto em casa de vegetação (PODESTÁ et al., 2016), quanto em condições de campo (BONTEMPO et al., 2017), além de promover $\mathrm{o}$ crescimento vegetal $\mathrm{e}$ solubilizar fosfato inorgânico (GOUVEIA et al., 2019).

Diante da expressividade da cafeicultura para a economia capixaba e dos resultados obtidos pelos diversos métodos de controle em estudos anteriores, objetivou-se potencializar o controle de $M$. exigua no substrato infestado, associando o tratamento biológico aos tratamentos químico e térmico do solo, de modo a reduzir os riscos oriundos dessa importante fonte de infestação na produção das mudas de café.

\section{MATERIAIS E MÉTODOS}

O experimento foi realizado no Instituto Federal do Espírito Santo, campus Santa Teresa, no distrito de São João de Petrópolis, latitude de $19^{\circ} 48^{\prime} \mathrm{S}$, longitude de $40^{\circ} 40^{\prime} \mathrm{W}$ e altitude de 137 metros, entre dezembro de 2017 e outubro de 2018.

\subsection{COLETA E PREPARO DO SUBSTRATO}

O substrato utilizado foi constituído unicamente de solo, retirado na rizosfera de cafeeiros arábica, variedade Catuaí, sabidamente infestados por nematoides na 
localidade de Alto Caldeirão, município de Santa Teresa. O solo coletado foi homogeneizado e peneirado para separação de torrões e raízes. Foi analisado quimicamente, cujo resultado foi $\mathrm{o}$ seguinte: Fósforo Mehlich $=13 \mathrm{mg} \backslash \mathrm{dm}^{3}$; Potássio $(\mathrm{K})=15 \mathrm{mg} \mathrm{dm}^{3}$; Enxofre $(\mathrm{S})=5$ mg $\backslash \mathrm{dm}^{3}$; Cálcio (Ca) = 5,1 $\mathrm{cmol} \mathrm{dm}^{3}$; Magnésio $(\mathrm{Mg})=1 \mathrm{cmol} \backslash \mathrm{dm}^{3} ; \mathrm{pH}$ em $\mathrm{H}_{2} \mathrm{O}=6,1$; Matéria Orgânica = 3,5dag $\backslash k g$.

\subsection{ESPÉCIE E POPULAÇÃO INICIAL DE NEMATOIDES NO SUBSTRATO}

Amostra de raízes dos cafeeiros foi retirada do solo coletado e enviada ao laboratório de Fitopatologia da Universidade Federal de Viçosa (UFV), para reconhecimento da espécie. Conforme laudo $\mathrm{n}^{\circ} 03 \backslash 2018$, emitido pelo Laboratório de Nematologia do Departamento de Fitopatologia da UFV, identificou-se a presença de $M$. exigua na amostra. A identificação foi feita pela técnica de Eletroforese de isoenzimas (Esterases).

Para extração e quantificação da população inicial dos nematoides foram tomadas três subamostras de $200 \mathrm{~cm}^{3}$ do solo e passadas em peneira fina para separação dos fragmentos de raízes. Realizou-se de cada subamostra, a extração de ovos e juvenis de segundo estádio (J2) do solo, conforme metodologia proposta por Jenkins (1964). Das raízes resultantes (10g), realizou-se a extração de ovos e J2, pela técnica do liquidificador associada a flotação centrífuga em solução de sacarose mais caulim, conforme método de Coolen \& D’Herde (1972).

Após as extrações, realizou-se a contagem de ovos e J2 com auxílio da câmara de Peters ao microscópio óptico. A população inicial de $M$. exigua foi de 2180 ovos $+\mathrm{J} 2$ por $200 \mathrm{~cm}^{3}$ de solo, obtida por meio da média de ovos $+\mathrm{J} 2$ encontrados nas subamostras de solo + raízes.

\subsection{APLICAÇÃO DOS TRATAMENTOS}

O delineamento experimental foi em blocos ao acaso, em esquema fatorial $4 \times 2$ com três repetições, totalizando 24 unidades experimentais. Cada unidade experimental foi composta por oito sacolas contendo, individualmente, o respectivo substrato e uma muda de café arábica, cultivar Catuaí Vermelho IAC 144.

No fator um os tratamentos dos substratos, foram: 1- Solo naturalmente infestado e sem tratamento; 2- Solo naturalmente infestado e tratado quimicamente com metam-sódico (383g. $\mathrm{Kg}^{-1}$ do i.a.); 3 - Solo naturalmente infestado e tratado quimicamente com dazomet (980g. $\mathrm{Kg}^{-1}$ do i.a.); 4 - Solo naturalmente infestado e tratado com energia solar. No fator dois, as opções de tratamento foram: 1 - não incorporação do agente de controle biológico $P$. chlamydosporia ao substrato tratado; 2 incorporação do agente de controle biológico $P$. chlamydosporia cepa Pc10 (280g. $\mathrm{Kg}^{-1}$ do i.a.) ao substrato tratado.

O metam-sódico foi aplicado na dosagem de $500 \mathrm{ml}$ do produto comercial por metro cúbico de solo, feito com o auxílio de um regador na proporção de três partes de água para uma parte do produto (3:1), distribuído sobre o solo úmido $\mathrm{e}$ misturado homogeneamente. O dazomete foi aplicado na dosagem de $250 \mathrm{~g}$ do produto comercial, por metro cúbico de solo, distribuído uniformemente sobre sua camada e em seguida regado até a capacidade de campo.

Por se tratar de produtos fumigantes, as porções de solo submetidas à aplicação de metam-sódico e de dazomete, foram contidas, separadamente, em recipiente plástico de 30 litros. Imediatamente após incorporação dos referidos produtos, os recipientes foram cobertos com filme plástico transparente e selados, a fim de evitar a fuga dos gases. Assim permanecendo por três e meio e nove dias, respectivamente. Transcorrido o período, os recipientes foram descobertos, 
o solo revolvido e exposto por nove e quatro dias, respectivamente, para aeração e liberação dos gases.

Após tratamentos, amostras do solo tratado com metam-sódico e dazomete foram colocados, individualmente, em frascos de vidro. Uma porção de solo não tratado foi também colocado em outro frasco de vidro para servir de comparativo (testemunha) aos tratamentos químicos. Sobre as porções de solo colocou-se um algodão embebido com água. Sementes de couve folha (Brassica oleracea) foram distribuídas uniformemente sobre o algodão e os recipientes foram fechados. Após quatro dias, avaliou-se a emergência das plântulas e verificou-se que $100 \%$ das sementes germinaram, garantindo a total dissipação dos gases nos substratos tratados quimicamente.

O solo infestado submetido ao tratamento térmico, foi acomodado nos tubos do coletor solar, com exposição na face norte em um ângulo de inclinação semelhante à latitude local $\left(19^{\circ}\right)$, acrescido de $10^{\circ}$ de acordo com Ghini (2004), por três dias.

Após finalização dos tratamentos químicos e solar, metade das porções de solos tratadas, inclusive da porção não tratada que compõe o tratamento testemunha, foram incorporados com $P$. chlamydosporia cepa Pc10. Foi aplicado a dose de $175 \mathrm{~g}$ do produto comercial por metro cúbico de solo. A formulação do produto foi dissolvida em água e pulverizada nas porções de solo úmido, correspondente aos respectivos tratamentos e em seguida homogeneizado para mistura da suspensão do inóculo ao solo, permanecendo em repouso em recipiente plástico por 12 dias.

As mudas foram produzidas em viveiro utilizando-se semente de café arábica, cultivar Catuaí Vermelho IAC 144, suscetível ao nematoide das galhas. As sementes foram obtidas de um produtor de Marechal Floriano - ES, devidamente registrado no Registro Nacional de
Sementes e Mudas do MAPA. Em dezembro de 2017 as sementes foram semeadas em areia esterilizada em autoclave a $121^{\circ} \mathrm{C}$ e 1 Kgf.cm ${ }^{-2}$ de pressão por uma hora. A autoclavagem da areia foi repetida após 24 horas.

As mudas em estágio "orelha de onça”, aos 60 dias após a semeadura, foram transplantadas para as sacolas de polietileno perfuradas medindo $18 \times 11 \mathrm{~cm}$, contendo substratos oriundos dos respectivos tratamentos. No viveiro as mudas foram mantidas sobre bancadas construídas de réguas de madeira, dispostas no sentido lesteloeste, por um período de 180 dias, recebendo irrigação controlada e eventual controle a pragas e plantas daninhas.

\subsection{AVALIAÇÃO DOS TRATAMENTOS}

\subsubsection{População de Nematoides}

Para avaliar a população de nematoides, quantificou-se o número de galhas por sistema radicular (NGR), o número de ovos $+\mathrm{J} 2$ extraídos por grama de raízes (PNR) e o número de ovos + J2 extraídos por centímetro cúbico de solo (PNS). Para extração dos nematoides das raízes utilizou-se a metodologia proposta por Coolen \& D'Herde (1972). Para extração dos nematoides do solo utilizouse a metodologia proposta por Jenkins (1964). Após as extrações, a contagem de ovos + J2 foi realizada com auxílio da lâmina de Peters ao microscópio óptico.

\subsubsection{Eficiência Controle}

A eficiência controle foi calculada pela diferença entre a média de ovos $+\mathrm{J} 2$ encontrados no tratamento testemunha (solo não tratado) e nos demais tratamentos (químicos e térmico) pelo quociente da média dos resultados encontrados no tratamento testemunha. O resultado foi multiplicado por 100 . 


\subsection{ANÁLISE DOS DADOS}

As variáveis avaliadas foram submetidas ao teste de normalidade de Liliefors e homogeneidade de variâncias ao teste de Cochran \& Bartlett, ao nível de 5\% de probabilidade. Após verificar que as pressuposições (normalidade e homogeneidade) da análise de variância foram atendidas, prosseguiu-se com a análise de variância. As médias dos tratamentos foram comparadas pelo teste Tukey ao nível de 5\% de probabilidade.

\section{RESULTADOS E DISCUSSÃO}

Observou-se que todos os tratamentos resultaram em redução significativa no número de galhas, de ovos e de $\mathrm{J} 2$ associados às raízes das mudas de cafeeiros crescidas sobre os substratos tratados. Entretanto, nenhum dos tratamentos resultou na eliminação completa das formas juvenis de $M$. exigua associado às raízes (Tabela 1 ).

$\mathrm{O}$ tratamento térmico do solo reduziu significativamente o número de galhas e o número de ovos e $\mathrm{J} 2$ nas raízes, independente da associação ou não do tratamento biológico com $P$. chlamydosporia. Entretanto, houve a formação de galhas associadas ao sistema radicular das mudas formadas sobre 0 substrato tratado termicamente. Esse fato indica que o tratamento térmico não foi eficaz em matar formas juvenis dentro dos ovos.

Vieira Júnior et al. (2019) estudando tipos diferentes de coletor solar - com tubos de aço galvanizado e com tubos de PVC, trataram solo infestado de $M$. incognita por 3 dias para experimento com feijão. Observaram no segundo dia, temperatura de $65^{\circ} \mathrm{C}$ por 3 horas em ambos os tipos e concluíram que foi eficiente para a desinfecção do substrato.

O tratamento do solo com os respectivos produtos químicos, também reduziram significativamente o número de galhas e o número de ovos e J2 nas raízes, independente da associação com $P$. chlamydosporia. No entanto houve interação do tratamento com dazomete e a associação de $P$. chlamydosporia para as variáveis número de ovos no solo e número de $\mathrm{J} 2$ nas raízes, reduzindo o inóculo em comparação ao mesmo tratamento sem a associação do agente de biocontrole.

Metam-sódico e dazomete são fumigantes de solo, que visam a desinfecção e desinfestação do solo para posterior semeadura ou introdução de plantas. Têm ação fungicida, nematicida e herbicida. Quando em contato com umidade, sofrem uma lenta decomposição química, com a formação de gases que apresentam efeito biocida (BARNARD et al., 1994).

Em trabalhos anteriores realizados para avaliar a eficiência do tratamento térmico e químico em solo infestado por M. exigua para produção de mudas de C. arabica (RODRIGUES, 2015), e por $M$. incognita para produção de mudas de C. canephora (BRUMAT, 2015), constataram redução significativa de galhas em ambos os métodos de tratamento. No entanto, os ingredientes ativos químicos aplicados ao solo não reduziram o quantitativo de ovos nas raízes em relação ao tratamento testemunha, indicando que os fumigantes afetam os juvenis presentes no solo, mas não aqueles que estariam dento dos ovos.

Houve diferença significativa na eficácia de controle proporcionada pelos tratamentos químico e térmico do substrato em relação ao tratamento testemunha (solo infestado e não tratado). Havia expectativa que a incorporação de $P$. chlamydosporia aos respectivos substratos promoveria redução significativa no quantitativo de ovos presentes. Não observou melhoria na eficácia do controle com a incorporação do agente de biocontrole aos respectivos substratos. 
Tabela 1. População final de M. exigua (ovos e J2) no solo e raízes de mudas de café arábica cv. Catuaí Vermelho IAC 144 crescidas em substratos submetidos a tratamentos químico e térmico, associados ou não com o agente microbiológico de controle P. chlamydosporia (P. c.).

\begin{tabular}{|c|c|c|c|c|c|c|c|c|c|c|c|c|}
\hline \multirow{3}{*}{$\begin{array}{l}\text { Tratamento do } \\
\text { substrato }\end{array}$} & \multicolumn{4}{|c|}{ Substrato } & \multicolumn{4}{|c|}{ Raízes } & \multirow{2}{*}{\multicolumn{2}{|c|}{$N^{0}$ de galhas }} & \multirow{2}{*}{\multicolumn{2}{|c|}{$\begin{array}{l}\text { Eficiência de } \\
\text { controle (\%) }\end{array}$}} \\
\hline & \multicolumn{2}{|c|}{ Ovos } & \multicolumn{2}{|c|}{ J2 } & \multicolumn{2}{|c|}{ Ovos } & \multicolumn{2}{|c|}{ J2 } & & & & \\
\hline & s\P.c. & c\P.c. & s\P.c. & c\P.c. & s\P.c. & c\P.c. & s\P.c. & c\P.c. & s\P.c. & c\P.c. & s\P.c. & c\P.c. \\
\hline Não Tratado & $0,000 \mathrm{Ab}$ & 0,000Aa & $2,113 \mathrm{Aa}$ & 1,930Aa & $1588,7 \mathrm{Aa}$ & $1123,5 \mathrm{Aa}$ & $426,0 \mathrm{Aa}$ & $298,9 \mathrm{Aa}$ & $107,7 \mathrm{Aa}$ & $31,8 \mathrm{Aa}$ & $0,00 \mathrm{Ab}$ & $23,76 \mathrm{Ab}$ \\
\hline Metam sódico & $0,11 \mathrm{Aab}$ & $0,057 \mathrm{Aa}$ & $1,720 \mathrm{Aa}$ & $1,280 \mathrm{Aa}$ & $86,7 \mathrm{Ab}$ & $80,9 A b$ & $6,5 \mathrm{Ab}$ & 4,8Ab & $0,0 \mathrm{Ab}$ & $0,0 \mathrm{Ab}$ & 79,16Аa & 84,79Aa \\
\hline Dazomete & 0,387Aa & $0,000 \mathrm{Ba}$ & 2,833Aa & $2,000 \mathrm{Aa}$ & $23,0 \mathrm{Ab}$ & $0,0 \mathrm{Ab}$ & $38,0 \mathrm{Ab}$ & $2,5 \mathrm{Bb}$ & $0,0 \mathrm{Ab}$ & $0,0 \mathrm{Ab}$ & $70,47 \mathrm{Aa}$ & 77,79Aa \\
\hline Coletor solar & $0,000 \mathrm{Ab}$ & $0,000 \mathrm{Aa}$ & $2,390 \mathrm{Ba}$ & $3,220 \mathrm{Aa}$ & $18,7 \mathrm{Ab}$ & $0,9 \mathrm{Ab}$ & $16,9 \mathrm{Ab}$ & $23,1 \mathrm{Ab}$ & $3,2 \mathrm{Ab}$ & $5,2 \mathrm{Ab}$ & 77,09Aa & 69,8Aab \\
\hline DMS & 0,280 & 0,128 & 1,661 & 2,764 & 1026,2 & 423,5 & 245,1 & 63,4 & 66,3 & 25,0 & 16,49 & 47,77 \\
\hline EC (\%) & 86,303 & 346,41 & 28,059 & 50,166 & 91,4 & 53,7 & 76,9 & 29,4 & 91,4 & 103,3 & 11,13 & 28,53 \\
\hline
\end{tabular}

*Médias seguidas da mesma letra maiúscula, na linha, não diferem entre si, pelo teste Tukey a 5\% de probabilidade.

**Médias seguidas da mesma letra minúscula, na coluna, não diferem entre si, pelo teste Tukey a 5\% de probabilidade.

Fonte: Do próprio autor (Santa Teresa - ES, 2018). 
O principal modo de ação de $P$. chlamydosporia contra os nematoides é o parasitismo de ovos e fêmeas. No entanto, produzem também enzimas e toxinas que alteram os exsudatos radiculares, afetando o desenvolvimento dos nematoides (DALLEMOLE-GIARETTA et al., 2012). As enzimas VCP1 e SCP1 produzidas pelo fungo, são capazes de degradar a camada lipídica e de corromper as camadas vitelinas de quitina e a proteína dos ovos de Meloidogyne spp. (ESCUDERO et al., 2016). É possível que a adição de $P$. chlamydosporia após o tratamento com dazomete, tenha resultado efeito parasitário do fungo sobre os ovos remanescentes de $M$. exigua no solo e por consequência reduzido o número de $\mathrm{J} 2$ nas raízes.

A associação de $P$. chlamydosporia ao solo infestado por $M$. exigua e não tratado, não reduziu significativamente qualquer das variáveis. Entretanto, reduziu parcialmente o número de galhas e de ovos e J2 das raízes quando comparado a não associação do fungo aos substratos. Podestá et al. (2009) observaram ao incorporar $P$. chlamydosporia em solo natural inoculado com Meloidogyne javanica em mudas de tomate, que houve redução do número de galhas e de ovos quando comparados com a não incorporação do fungo ao solo.

Segundo Dallemole-Giaretta (2012) a incorporação desse fungo ao solo precisa ser feita antes do plantio. Possibilitando que o fungo se estabeleça no solo e parasite os ovos, impedindo a eclosão e formação do J2, a infestação das raízes, a formação das galhas, e consequentemente a produção dos novos ovos pelas fêmeas. Entretanto, as condições ambientais no viveiro de produção de mudas de café, proporcionadas pelo excesso de umidade, pode interferir na sobrevivência e na ação antagônica desse agente de biocontrole. Especula-se que isso seja uma das razões pela qual a eficácia de controle não tenha sido significativa a partir da incorporação do fungo antagonista aos substratos tratados e não tratados.

\section{CONCLUSÕES}

Os tratamentos térmico e químico do substrato, associados ou não com $a$ P. chlamydosporia reduziram significativamente o número de galhas e a população de nematoides (ovos $+\mathrm{J} 2$ ) nas raízes. A eficiência de controle foi melhorada pelos tratamentos térmico e químico em relação ao substrato não tratado.

\section{AGRADECIMENTOS}

A FAPES pelo suporte financeiro (Número do Protocolo 28419.421.18764.11062015) e ao Ifes pelo apoio estrutural no desenvolvimento da pesquisa.

\section{REFERÊNCIAS}

BARBOSA, R. T.; MONTEIRO, T. S. A.; COUTINHO, R. R.; SILVA, J. G.;

FREITAS, L. G. Pochonia chlamydosporia no controle do nematoide de galhas em bananeira. Nematropica. v. 49, n. 1, p. 99106, 2019.

\section{BARROS, A. F. Caracterização de populações de Meloidogyne spp. em cafezais do estado do Espírito Santo e da Zona da Mata de Minas Gerais. Viçosa- MG: UFV, 2010. Dissertação (Mestrado em Fitopatologia) - Universidade Federal de Viçosa.}

BELTRÃO, A. F. História Completa Café no Brasil. Revista Cafeicultura, Rio Paranaíba, MG, mar. 2018. Disponível em: https://revistacafeicultura.com.br/?mat=66 568. Acesso em 25 set. 2018.

BARNARD, E.L.; GILLY, S.P.; ASH, E.C. An Evaluation of Dazomet and Metam-Sodium Soil Fumigants for Control of Macrophomina phaseolina in a Florida 
Forest Nursery. Tree Planters' Notes v.45, n.3, p.91-95, 1994.

BONTEMPO, A. F.; LOPES, E. A.; FERNANDES, R. H.; FREITAS, L. G.; DALLEMOLE-GIARETTA, R. Doseresponse effect of Pochonia chlamydosporia against Meloidogyne incógnita on carrot under field conditions. Revista Caatinga, v. 30, n. 1, p. 258-26, 2017.

BRUMAT, A. C. L. Aplicação de tratamento térmico e químico no controle de Meloidogyne incognita em substrato para produção de mudas de Coffea canephora. Santa Teresa-ES: Ifes, 2015. Monografia (Graduação em Agronomia) - Instituto Federal do Espírito Santo.

CAMPOS, V. P.; VILLAIN, L. Nematode parasites of coffee and cocoa. In: LUC, M., R. SIKORA; J. BRIDGE (eds). Plant Parasitic nematodes in subtropical and tropical agriculture. 2.ed, Wallingford: CABI, p. 529- 579, 2005.

Conselho dos Exportadores de Café do Brasil (CECAFE). Resumo das exportações de café - dezembro 2019. Disponível em:

http://www.sapc.embrapa.br/arquivos/cons orcio/informe_estatistico/CECAFE_Relato rio_Mensal_DEZEMBRO_2019.pdf.

Acesso em: 22 set. 2020.

CONAB. Companhia Nacional de Abastecimento. Acompanhamento da safra brasileira de café. V. 6 - SAFRA 2020 - N.3 - Terceiro levantamento, Brasília, p. 8- 24, setembro 2020.

Disponível em: http://www.conab.gov.br. Acesso em 23 set. 2020.

COOLEN, W.A.; D'HERDE, C.J. A method for the quantitative extraction of nematodes from plant tissue. Ghent: State Nematology and Entomology Research Station, 1972. 77p.
DALLEMOLE-GIARETTA, R.; FREITAS, L.G. de; LOPES, E.A.; PEREIRA, O.I.; ZOOCA, R.J.F.; FERRAZ, S. Screening of Pochonia chlamydosporia Brazilian isolates as biocontrol agents of Meloidogyne javanica. Crop Protection, v.42, p. 102-107, 2012.

ESCUDERO, N.; FERREIRA, S. R.; LOPEZ-MOYA, F.; NARANJO-ORTIZ, M. A.; MARIN-ORTIZ, A. I.; THORNTON, C. R.; LOPEZ-LLORCA, L. $\mathrm{V}$. Chitosan enhances parasitism of Meloidogyne javanica eggs by the nematophagous fungus Pochonia chlamydosporia. Fungal Biology, v. 120, p. 572-585, 2016.

FERRAZ, L.C.C.B.; BROWN, D.J.F. Nematologia de plantas: fundamentos e importância. Manaus: NORMA EDITORA, 2016. 251p.

\section{GHINI, R. Coletor Solar para}

Desinfestação de Substratos para

Produção de Mudas Sadias. Jaquariúna, SP: Embrapa Meio Ambiente, maio de 2004 (Circular Técnica, 4).

GOUVEIA, A. D. S.; MONTEIRO, T. S. A.; VALADARES, S. V.; SUFIATE, B. L.; Freitas, L. G. de; Ramos, H. J. D. O.; Queiroz, J. H. de. Understanding How Pochonia chlamydosporia Increases Phosphorus Availability.

Geomicrobiology Journal. V. 36, n. 8, p. 1-5, 2019.

JENKINS, F. G. W. A rapid centrifugalflotation technique for extracting nematodes from soil. Plant Disease Reporter, v. 48, p. 692. 1964.

LIMA, I. M.; BUONICONTRO, D. S.; ARPINI, B. S.; TEODORO, M. C.; COSTA, N. S. Gerenciamento de nematoides no sistema de produção de cafeeiro conilon. In: Café Conilon: 
Conhecimento para Superar Desafios.

Alegre, p. 61-74, 2019.

MINISTÉRIO DA AGRICULTURA, PECUÁRIA E ABASTECIMENTO.

Produção de mudas de café no Espírito

Santo, inscritas no MAPA, dez. $\mid 2016$ a nov.|2017. SIFISV\DDA \SFA\ES. Vitória, 2017.

PODESTÁ, G. S.; AMORA, D. X.; MAFFIA, L. A.; NASU, E. G. C.; FERRAZ, S.; FREITAS, L.G. Effect of time between soil infestation with Pochonia chlamydosporia and planting on the efficacy of the fungus in managing Meloidogyne javanica. Crop Protection, v. 90, p. 77-83, 2016.

PODESTÁ, G. S.; DALLEMOLEGIARETTA, R.; FREITAS, L.G.; LOPES, E.A.; FERRAZ, S.; ZOOCA, R. J. F. Atividade nematófaga de Pochonia chlamydosporia em solo natural ou autoclavado sobre Meloidogyne javanica.

Nematologia Brasileira, 33: 191-193. 2009.

ROCHA, G. A; CARNEIRO, L. C. Solarização do solo associada à incorporação de material orgânico na redução da viabilidade de escleródios.

Revista De Ciências Agroambientais, v. 14, n. 1, 2016.

RODRIGUES, J. S. da. Aplicação de tratamento térmico e químico no controle de Meloidogyne exigua em substrato de mudas de Coffea arabica. Santa Teresa-ES: Ifes, 2015. Monografia (Graduação em Agronomia) - Instituto Federal do Espírito Santo.

\section{SECRETARIA DE ESTADO DA}

AGRICULTURA, DO

ABASTECIMENTO, AQUICULTURA E PESCA (Espírito Santo). "O melhor café é o capixaba!” Portal do Governo. Vitória, 2019. Disponível em: https://seag.es.gov.br > Notícia > o-melhorcafe-e-o-capixaba. Acesso em: 23 set. 2020.

SILVA, S. D. Avaliação da patogenicidade de isolados de Pochonia chlamydosporia e Purpureocillium lilacinum sobre ovos de Meloidogyne enterolobii. Brasília-DF: Faculdade de Agronomia e Medicina Veterinária, UnB, 2015. Dissertação (Mestrado em Agronomia) - Universidade de Brasília.

VIEIRA JÚNIOR, J. R.; FERNANDES, C. de F.; MATOS, S. I. de; SILVA, C. M. da; ANJOS, E. F. M. dos; FREIRE, T.C.; SANGI, S. C.; SOUZA, V. F. Efeito do tratamento térmico de solo por solarizador para produção de mudas livres de nematoides: adaptação do modelo de Ghini. Porto Velho, RO: Embrapa Rondônia, 2016. 23 p. - (Boletim de Pesquisa e Desenvolvimento / Embrapa Rondonia, ISSN 1677-8618; 79).

VIEIRA JÚNIOR, J. R.; ANJOS, E. F. M. dos; FERNANDES, C. de F.; MATOS, S. I. de; RUDNICK, V. A. S.; SANTOS, C. F.; SOUZA, C. F. de; SILVA, G. R. da; FIGUEIREDO, M. C. Coletor solar no tratamento de substrato contaminado por nematoide-das-galhas do cafeeiro. $X$ Simpósio de Pesquisa dos Cafés do Brasil. Vitória - ES, 2019.

WARD, E.; KERRY, B. R.; MANZANILLA-LÓPEZ, R. H.; MUTUA, G.; DEVONSHIRE, J.; KIMENJU, J.; HIRSCH, P. R. The Pochonia chlamydosporia serine protease Gene vcp1 is subject to regulation by carbon, nitrogen and $\mathrm{pH}$ : Implications for nematode biocontrol. PLOS One, San Francisco, v. 7, n. 4, p. e35657, 2012. 